\title{
Social Media in Medical Education
}

\author{
R.T. Fitzgerald, A. Radmanesh, and C.M. Hawkins
}

A

ccording to a 2011 survey, 94\% of medical students and $79.4 \%$ of residents in the United States are active on-line social media users. ${ }^{1}$ Social media represent a relatively simple technique to provide educational material in a format that is adapted to the learning styles preferred by the "millennial" generation. Evidence suggests that most incoming medical students are receptive to on-line learning tools even in the absence of prior exposure to such methods for educational purposes. ${ }^{2}$ However, despite all of the attention social media have received in medical education circles, it remains unclear how social media use can be optimized to educate communities of learners through information sharing and knowledge dissemination. ${ }^{3}$

Those of us engaged in the education of medical students, residents, and fellows have witnessed a transition in recent years from print textbooks, journals, and syllabi to predominantly electronic media. At many medical schools across the country, learning experience has in part shifted from classrooms into on-line platforms, commonly accessed through mobile devices. For instance, Stanford Medical School saw an increase in class attendance from $30 \%$ to $80 \%$ after transitioning much of the traditionally didactic classroom lessons into concise on-line sessions, and reserving classroom time for interactive discussions and problem solving. ${ }^{4}$ Similarly, many radiology programs, such as the program at the University of Arkansas for Medical Sciences, now use Web-based educational activities as an adjuvant to traditional didactic lectures. Advantages of electronic educational resources, or e-learning, include ease of access and physical transport, searchability, and the potential for interaction among trainees as well as between trainees and educators. ${ }^{3}$ Dissemination of electronic educational resources via social media leverages one of this format's strengths: information flow is based largely on relative value as judged by users. For example, popular or particularly valuable

From the Department of Radiology (R.T.F.), Neuroradiology Division, University of Arkansas for Medical Sciences, Little Rock, Arkansas; Department of Radiology and Biomedical Imaging (A.R.), University of California, San Francisco, San Francisco, California; and Emory University School of Medicine (C.M.H.), Atlanta, Georgia.

Please address correspondence to Ryan T. Fitzgerald, MD, Department of Radiology, Neuroradiology Division, University of Arkansas for Medical Sciences, 4301 W Markham St, Little Rock, AR 72205; e-mail: fitzgeraldryant@uams.edu;

@ryantfitzgerald

http://dx.doi.org/10.3174/ajnr.A4136 resources will be posted, "liked," retweeted, and "favorited" more often, thus gaining a wider audience than resources that are deemed less valuable.

As of 2011, most health professional students prefer to receive educational material on-line. ${ }^{5}$ Even beyond formal training, practicing physicians now have access to an increasing array of on-line sources for continuing medical education (CME) such as the American Society of Neuroradiology's eCME course catalog (http://members.asnr.org/ecme/) and American Academy of Neurology's on-line CME site (https://cme.neurology.org/s/ catalog). Social media represent an ideal way for professional organizations to disseminate new or updated on-line CME material to their members. Furthermore, social media also allow professional organizations to meaningfully interact with their members, collect feedback, and respond purposefully in a way that was not possible with traditional methods of member-organization communication.

In their review of social media use in medical education, Cheston et $\mathrm{al}^{3}$ report that the introduction of social media-based content favorably impacts learner satisfaction and knowledge. Social media succeed in accomplishing this in a number of ways. For educators, links to reading assignments or "case of the week" installments can be efficiently distributed to a group of followers using platforms such as Twitter. Hashtags can serve to archive current and past assignments, and to manage on-line group discussions on a particular topic. Tweet chats during and after lectures and journal clubs offer trainees the opportunity to ask questions and have discussions, or provide the group with links to related material in real time. Through such interactivity, social media channels promote knowledge sharing, rather than consumption of the material that is "pushed" to target audiences. In addition, participants in social media forums often have a variety of experiences and abilities, thus diversifying and enriching conversations.

The potentials of social media for medical education are only recently being realized, and robust evidenced-based data on this subject are lacking. In the coming years with the anticipated continuing shift of student preferences toward on-line content, increased interconnectivity, and peer-to-peer knowledge sharing, social media have the potential to substantially impact and dis- 
rupt medical education. The radiology community would be well served by leading this charge.

\section{REFERENCES}

1. Bosslet GT, Torke AM, Hickman SE, et al. The patient-doctor relationship and online social networks: results of a national survey. J Gen Intern Med 2011;26:1168-74
2. Sandars J, Morrison C. What is the net generation? The challenge for future medical education. Med Teach 2007;29:85-88

3. Cheston CC, Flickinger TE, Chisolm MS. Social media use in medical education. Acad Med 2013;88:893-901

4. Prober CG, Heath C. Lecture halls without lectures-a proposal for medical education. $N$ Engl J Med 2012;366:1657-59

5. Giordano C, Giordano C. Health professions students' use of social media. J Allied Health 2011;40:78-81 